Article

\title{
Changes of Phytochemical Components (Urushiols, Polyphenols, Gallotannins) and Antioxidant Capacity during Fomitella fraxinea-Mediated Fermentation of Toxicodendron vernicifluum Bark
}

\author{
Da-Ham Kim ${ }^{1}$, Min-Ji Kim ${ }^{1}$, Dae-Woon Kim ${ }^{1}$, Gi-Yoon Kim ${ }^{1}$, Jong-Kuk Kim ${ }^{1}$, \\ Yoseph Asmelash Gebru ${ }^{1}$, Han-Seok Choi ${ }^{2}$, Young-Hoi Kim ${ }^{1}$ and Myung-Kon Kim ${ }^{1 \text {,* }}$ \\ 1 Department of Food Science and Biotechnology, Chonbuk National University, Jeonju 54896, Jeonbuk, Korea; \\ dadaham@naver.com (D.-H.K.); kmj6202@hanmail.net (M.-J.K.); kdwoon1@naver.com (D.-W.K.); \\ seokmin0000@naver.com (G.-Y.K.); rlawodrnr@naver.com (J.-K.K.); yagebru@gmail.com (Y.A.G.); \\ yhoi1307@hanmail.net (Y.-H.K.) \\ 2 Department of Agriculture and Fisheries Processing, Korea National College of Agriculture and Fisheries, \\ Jeonju 54874, Jeonbuk, Korea; coldstone@korea.kr \\ * Correspondence: kmyuko@jbnu.ac.kr; Tel.: +82-63-270-2551; Fax: +82-63-270-2572
}

Academic Editors: Marian Brestic, Marek Zivcak, Oksana Sytar and Marco Landi Received: 21 December 2018; Accepted: 10 February 2019; Published: 14 February 2019

\begin{abstract}
The stem bark of Toxicodendron vernicifluum (TVSB) has been widely used as a traditional herbal medicine and food ingredients in Korea. However, its application has been restricted due to its potential to cause allergies. Moreover, there is limited data available on the qualitative and quantitative changes in the composition of its phytochemicals during fermentation. Although the Formitella fraxinea-mediated fermentation method has been reported as an effective detoxification tool, changes to its bioactive components and the antioxidant activity that takes place during its fermentation process have not yet been fully elucidated. This study aimed to investigate the dynamic changes of urushiols, bioactive compounds, and antioxidant properties during the fermentation of TVSB by mushroom $F$. fraxinea. The contents of urushiols, total polyphenols, and individual flavonoids (fisetin, fustin, sulfuretin, and butein) and 1,2,3,4,6-penta-O-galloyl- $\beta$-D-glucose (PGG) significantly decreased during the first 10 days of fermentation, with only a slight decrease thereafter until 22 days. Free radical scavenging activities using 2,2-diphenyl-1-picrylhydrazyl (DPPH), 2,2'-azino-bis(3-ethylbenzothiazoline-6- sulfonic acid) (ABTS), and ferric reducing/antioxidant power (FRAP) as an antioxidant function also decreased significantly during the first six to nine days of fermentation followed by a gentle decrease up until 22 days. These findings can be helpful in optimizing the $F$. fraxinea-mediated fermentation process of TVSB and developing functional foods with reduced allergy using fermented TVSB.
\end{abstract}

Keywords: Toxicodendron vernicifluum; Fomitella fraxinea; fermentation; urushiols; polyphenols; antioxidant activity

\section{Introduction}

Toxicodendron vernicifluum (TVSB, Stokes) F. Barkley (formerly known as Rhus verniciflua Stokes) belongs to the Anacardiaceae family [1], and is widely distributed in China, Japan, and Korea [2]. It is commonly known as the lacquer tree or vanish tree (also known as sumac). The stem and bark of T. vernicifluum have traditionally been used as folk medicines for treating blood disorders, hepatic disorders, gastric disorders, inflammatory diseases, anti-aging, paralysis, hypertension, and various cancers, as well as materials for lacquered chicken and duck soup recipes in Korea [3-5]. 
The xylem and bark of T. vernicifluum have also been reported to possess strong antioxidant [6,7], antiplatelet [8,9], immune-enhancing [10], neuroprotective [11,12], anti-inflammatory [12,13], and anti-cancer activities $[4,14,15]$. These health benefits were found to be attributed to the presence of flavonoids, gallotannins, and phenolic acids $[3,16]$. However, urushiol congeners found in the plant can cause allergic contact dermatitis with irritation, inflammation, and blistering in sensitive individuals $[17,18]$. Various methods have been attempted to remove or reduce urushiol congeners from the xylem and bark of T. vernicifluum, including physicochemical treatments such as solvent extraction, pyrolysis at high temperature, and enzymatic methods. Although some of these methods are effective at removing urushiols, they have limitations such as the generation of harmful substances, high cost, process complexity, and low efficiency [19].

A new biological method has been introduced to remove urushiols through fermentation with Basidiomycete Formitella fraxinea as an alternative method to solve these problems. This method was able to efficiently decrease more than $90 \%$ of the urushiols in TVSB [19]. Recently, an aqueous extract of urushiol-free fermented TVSB by $F$. fraxinea has been approved for use in soy sauce, fermented vinegar, and some alcoholic beverages by the Korea Food and Drug Administration (KFDA) [20], and its extracts are currently being marketed as functional health foods in Korea. Many studies on the biological activities of TVSB fermented by $F$. fraxinea have been reported, and most of these results were obtained by fermentation with $F$. fraxinea for $20-28$ days $[5,7,11,21,22]$. While the fermentation method using $F$. fraxinea is being accepted as an effective tool to remove urushiols in TVSB, the dynamic changes of its bioactive components such as total polyphenols, individual phenolic compounds, gallotannins, and antioxidant activity during the fermentation process have not yet been fully elucidated. Flavonoids (fustin, fisetin, sulfuretin, and butein), PGG, and gallic acid as a gallotannin group are considered the major active constituents that are responsible for the various biological effects of TVSB [9,23-25]. Therefore, the objective of this study was to investigate dynamic changes in the polyphenols, individual phenolic compounds, gallotannins, and antioxidant activity during the fermentation of TVSB by mushroom $F$. fraxinea.

In this study, we demonstrated the optimization of an effective detoxification of urushiol congeners in TVSB through monitoring fermentation time while simultaneously intending to achieve a minimized loss of other useful phenolic compounds. The optimal fermentation period to achieve the desired detoxification effect was found to be 13-16 days. This finding provides valuable information to reconsider the common practice of fermenting TVSB extracts with $F$. fraxinea for 20-28 days prior to their applications in Korea.

\section{Results and Discussion}

\subsection{Changes of Urushiols}

Although TVSB has attracted much attention since ancient times in Korea due to its beneficial properties to human health, its allergenic urushiol congeners have limited its application in the food and pharmaceutical industries. Moreover, the contents of urushiols in T. verniciflua are higher in the bark than in its xylem. Therefore, it is necessary to remove its urushiol congeners during food or pharmaceutical applications. It has been reported that fermentation with $F$. fraxinea is an effective way to remove toxic urushiols from TVSB, and that mushroom laccases play an important role in the detoxification [19]. In this study, changes of urushiol congeners during F. fraxinea-mediated fermentation were analyzed by HPLC. As shown in Figure 1A, pentadecatrienylcatechol $\left(C_{15: 3}\right)(671.08$ $\pm 25.43 \mu \mathrm{g} / \mathrm{g}$ dry weight (DW)) was the most abundant, followed by pentadecenylcatechol $\left(\mathrm{C}_{15: 1}\right)$ $\left(461.80 \pm 4.95 \mu \mathrm{g} / \mathrm{g}\right.$ DW) and pentadecadienylcatechol $\left(\mathrm{C}_{15: 2}\right)(95.77 \pm 6.43 \mu \mathrm{g} / \mathrm{g} \mathrm{DW})$ in unfermented TVSB (UTVSB). The content of $C_{15: 3}$ rapidly decreased from $671.08 \pm 25.43 \mu \mathrm{g} / \mathrm{g}$ DW in UTVSB to $115.22 \pm 11.14 \mu \mathrm{g} / \mathrm{g}$ DW $(82.8 \%$ decrease $)$ and $48.61 \pm 6.51 \mu \mathrm{g} / \mathrm{g}$ DW $(92.8 \%$ decrease $)$ after 10 and 13 days of fermentation, respectively. Thereafter, it showed only a slow decrease, reaching $30.66 \pm$ $2.70 \mu \mathrm{g} / \mathrm{g}$ DW (95.4\% decrease) at the end of the fermentation process (22 days). The $\mathrm{C}_{15: 2}$ and $\mathrm{C}_{15: 1}$ 
contents also decreased in a similar pattern to that of $\mathrm{C}_{15: 3}$. The control was incubated for the same time intervals as the fermented sample. However, HPLC analysis of the controls was carried out only for 0 and 22-day time points, because the thin-layer chromatography (TLC) results (Supplementary Data Figures S1-S4) showed no difference among all of the matched controls. When the TVSB was treated under the sample conditions, but without F. fraxinea inoculation as the matched control, no meaningful changes were observed, even after 22 days compared to zero days (Supplementary Data, Figures $\mathrm{S} 1-\mathrm{S} 4)$. These results suggest that the gradual decreases of urushiols during fermentation are due to the action of related enzymes secreted from F. fraxinea.

The total content of urushiol congeners decreased from $1228.7 \pm 34.6 \mu \mathrm{g} / \mathrm{g}$ DW in UTVSB to $186.02 \pm 24.3 \mu \mathrm{g} / \mathrm{g}$ DW $(84.9 \%), 78.77 \pm 11.2 \mu \mathrm{g} / \mathrm{g} \mathrm{DW}(93.6 \%)$, and $47.75 \pm 9.5 \mu \mathrm{g} / \mathrm{g} \mathrm{DW}(96.1 \%$ decrease) at the end of 10,13, and 22 days of fermentations, respectively (Figure 1B). Considering these results, the optimal fermentation period for the removal or reduction of urushiol congeners from TVSB by F. fraxinea is suggested to be between 13-16 days of fermentation. Choi et al. [19], who attempted a similar biological method for the reduction of urushiols, reported that the content of $C_{15: 3}$ decreased rapidly in the first five days of fermentation, followed by a gradual decrease, reaching the lowest levels after 15 days of fermentation.

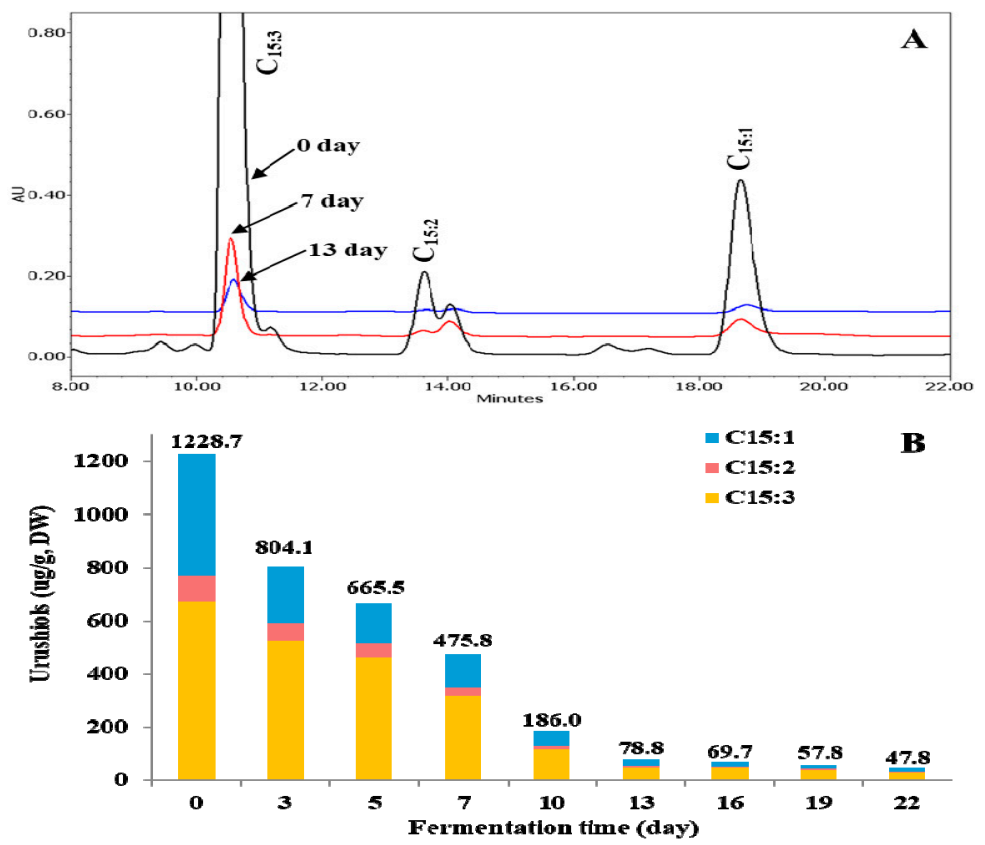

Figure 1. Changes of urushiol congeners during fermentation of Toxicodendron vernicifluum stem bark (TVSB) by F. fraxinea. Representative HPLC chromatograms (A) and contents (B).

The degradation of urushiols is closely associated with the laccase that is secreted from $F$. fraxinea mycelia. Laccase is a type of copper-containing polyphenol oxidase ( $p$-diphenol oxidase or benzenediol; oxygen oxidoreductase, EC 1.10.3.2). More than 100 fungal laccases have been purified and characterized from Basidiomycetes and Ascomycetes [26]. Since these enzymes can catalyze the oxidation of phenolic compounds such as polyphenols, methoxy-substituted phenols, $o$-diphenols, $p$-diphenols, aromatic amines, and syringaldazine, it is somewhat difficult to categorize laccases based on the type of substrates, because a wide range of substrates can be catabolized [26-28]. However, laccase can oxidize urushiols and result in the formation of semiquinone radicals under aerobic conditions. This is a typically unstable product, and it undergoes subsequent changes either through an attack on the urushiol nucleus, forming biphenyl compounds, or a disproportionation reaction to give urushiol quinone [29]. It may also undergo polymerization reactions, which results in the formation of a conjugated insoluble product. All of these mechanisms lead to the reduction of the active site of urushiols, thereby resulting in its detoxification $[29,30]$. 


\subsection{Change of Total Phenol, Total Flavonoid, and Individual Flavonoid}

The diverse pharmacological activities of T. vernicifluum are believed to be mainly attributed to the presence of phenolic compounds such as fustin, fisetin, sulfuretin, quercetin, taxifolin, garbanzol, butein, gallic acid, dihydroxybenzoic acids, and other phenolic compounds [24,25]. It is known that fustin, fisetin, sulfuretin, and butein are abundant in the bark and xylem of T. vernicifluum [12,13]. Therefore, it is necessary to minimize the degradation of these valuable bioactive components during fermentation. Changes to the total phenol and total flavonoid contents in TVSB during F. fraxinea-mediated fermentation were investigated.

The total phenol content decreased sharply from $2927.6 \pm 228.8 \mathrm{mg}$ GAE/100 $\mathrm{g}$ DW in UTVSB to $859.2 \pm 156.6 \mathrm{mg}$ GAE/100 g DW after 10 days of fermentation, reaching $599.3 \pm 78.1 \mathrm{mg}$ GAE/100 $\mathrm{g} \mathrm{DW}$ at the end of the fermentation (Figure 2A). The total flavonoid content decreased from $1365.4 \pm 130.6 \mathrm{mg} \mathrm{RE} / 100 \mathrm{~g}$ DW in UTVSB to $598.3 \pm 64.5 \mathrm{mg} \mathrm{RE} / 100 \mathrm{~g} \mathrm{DW}$ and $272.8 \pm$ $39.6 \mathrm{mg} \mathrm{RE} / 100 \mathrm{~g}$ DW after 10 and 22 days of fermentation, respectively (Figure $2 \mathrm{~B}$ ). The reduction of total phenol and total flavonoid during fermentation is closely associated with the polyphenol oxidases that are secreted from F. fraxinea mycelia. Polyphenol oxidases (EC 1.14.18.1) that are known as tyrosinase, laccase, catechol oxidase, catecholase, phenolase, cresolase, and urushiol oxidase based on substrate specificity are known to have considerable overlap in substrate affinities [31,32]. These enzymes are distributed in a wide range of fungi, higher plants, and mammals. They can catalyze the oxidation of a broad range of phenolic compounds, including phenols, phenolic acids, flavonoids, tyrosine, L-3,4-dihydroxyphenylalanine (L-DOPA), naphthols, bisphenols, and other phenolic compounds $[28,31,33]$.
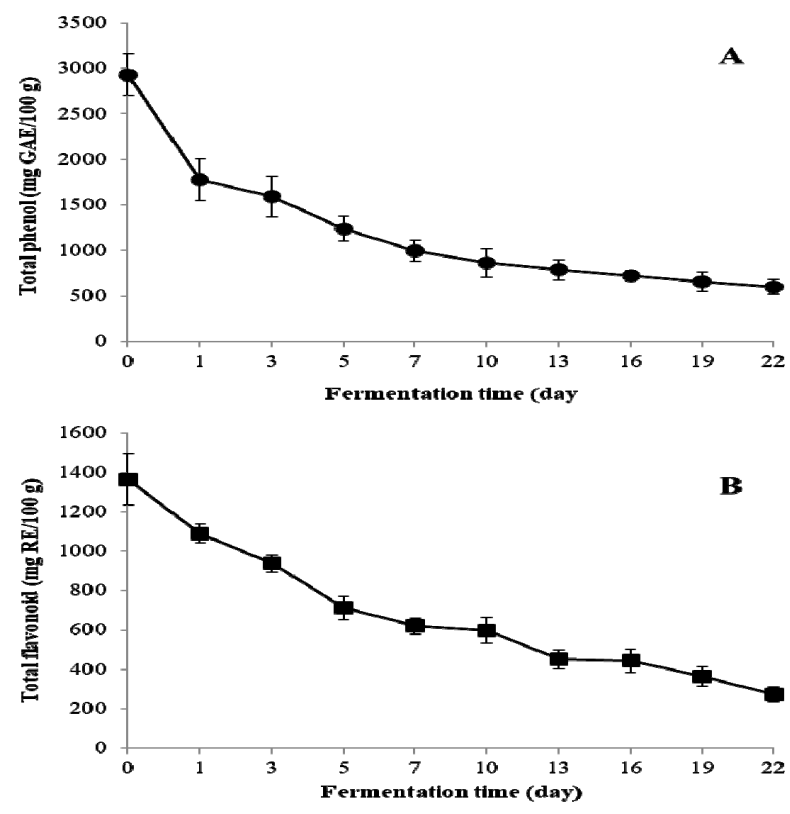

Figure 2. Changes in the contents of total phenol (A) and total flavonoid (B) during the fermentation of TVSB by F. fraxinea. Error bars are the standard deviations of triplicate measurements.

In this study, changes of individual flavonoids during fermentation were also monitored by HPLC analysis (Figure 3A). The contents of major flavonoids such as fustin, fisetin, sulfuretin, and butein showed noticeable decreases at the initial stage (five days) of fermentation, followed by gradual decreases up until 22 days (Figure 3B). It has been previously reported that basidiomycete polyphenol oxidases can effectively utilize flavonoids such as quercetin, fisetin, rutin, luteolin, myricetin, and kaempferol, as well as phenolic acids as substrates [28,31,33,34]. Therefore, the reduction of flavonoids that was observed during the fermentation of the TVSB extract is suggested to be mediated by polyphenol oxidases that are secreted from F. fraxinea. 


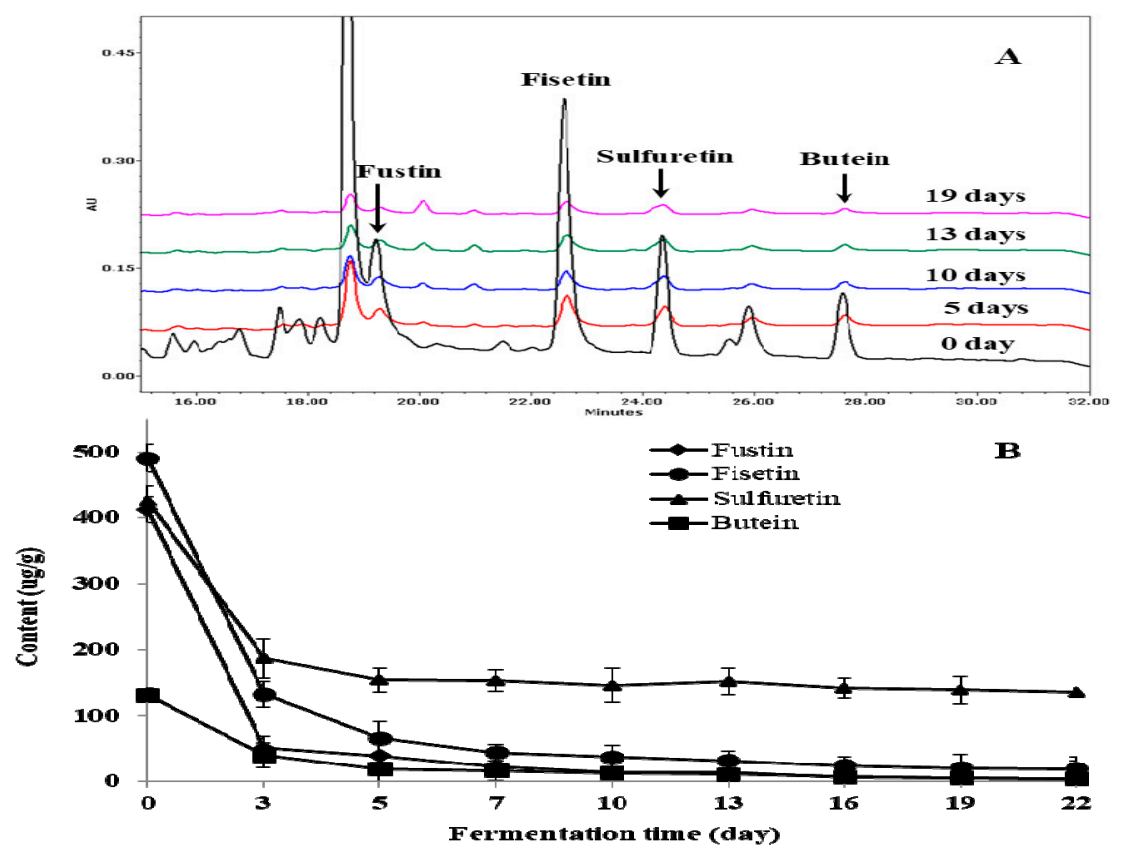

Figure 3. Changes of individual flavonoid compounds during the fermentation of TVSB by F. fraxinea. HPLC chromatograms (A), contents of individual flavonoids (B). Error bars are the standard deviations of triplicate measurements.

\subsection{Changes of $P G G$}

Gallotannin appears to have important biological roles including antioxidant, antibacterial, anti-inflammatory, anti-hypoglycemic, anti-angiogenic, and anti-cancer activities. 1,2,3,4,6-penta-O-galloyl- $\beta$-D-glucose (PGG), which is a gallotannin, are widely distributed in fruit, berries, and woody plants. PGG and its hydrolysates are among the main groups of antioxidant polyphenols in UTVSB. They have attracted attention in recent years due to their beneficial properties for human health [16,23]. In this study, PGG, gallic acid, and methyl gallate were detected as gallotannins in UTVSB.

PGG content decreased from $5590.0 \pm 324.5 \mu \mathrm{g} / \mathrm{g}$ DW in UTVSB to $1580.0 \pm 282.2 \mu \mathrm{g} / \mathrm{g}$ DW (71.7\% decrease) and $1452.9 \pm 211.9 \mu \mathrm{g} / \mathrm{g}$ DW (74.0\% decrease) after 10 and 13 days of fermentation, respectively. Only slight changes in PGG content were observed from day 13 to day 22 of fermentation (Figure 4). Gallic acid and methyl gallate contents also showed noticeable decreases within seven days from the start of fermentation.

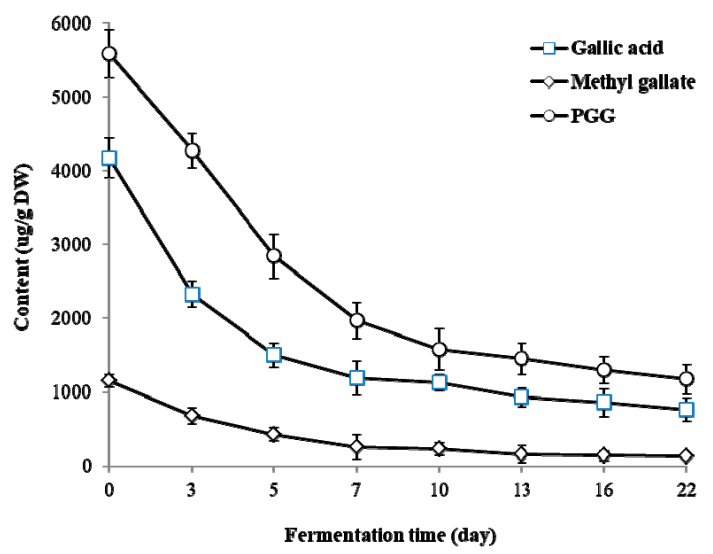

Figure 4. Changes of 1,2,3,4,6-penta-O-galloyl- $\beta$-D-glucose (PGG) and its metabolites gallic acid and methyl gallate during the fermentation of TVSB by F. fraxinea. Error bars are the standard deviations of triplicate measurements. 


\subsection{Characterization of PGG Hydrolysates by HPLC-MS}

Gallotannins are important bioactive compounds in medicinal plants. PGG is especially abundant in the TVSB [25]. This compound showed a consistent decrease during the initial stage of fermentation, as shown in Figure 4. HPLC analysis (Figure 5B) revealed the formation of new peaks in the $80 \%$ methanol extract of fermented TVSB that were not detected in the similar extract of UTVSB (Figure 5A). These peaks were then tentatively identified by HPLC-MS analysis. Total ion current (TIC) chromatograms of the $80 \%$ methanol extract from 10-day fermented TVSB and the hydrolysate of PGG by crude enzyme preparation isolated from fermented TVSB are shown in Figure 6. Forty-two compounds in the fermented TVSB and 40 compounds in PGG hydrolysate were identified tentatively (Table 1).
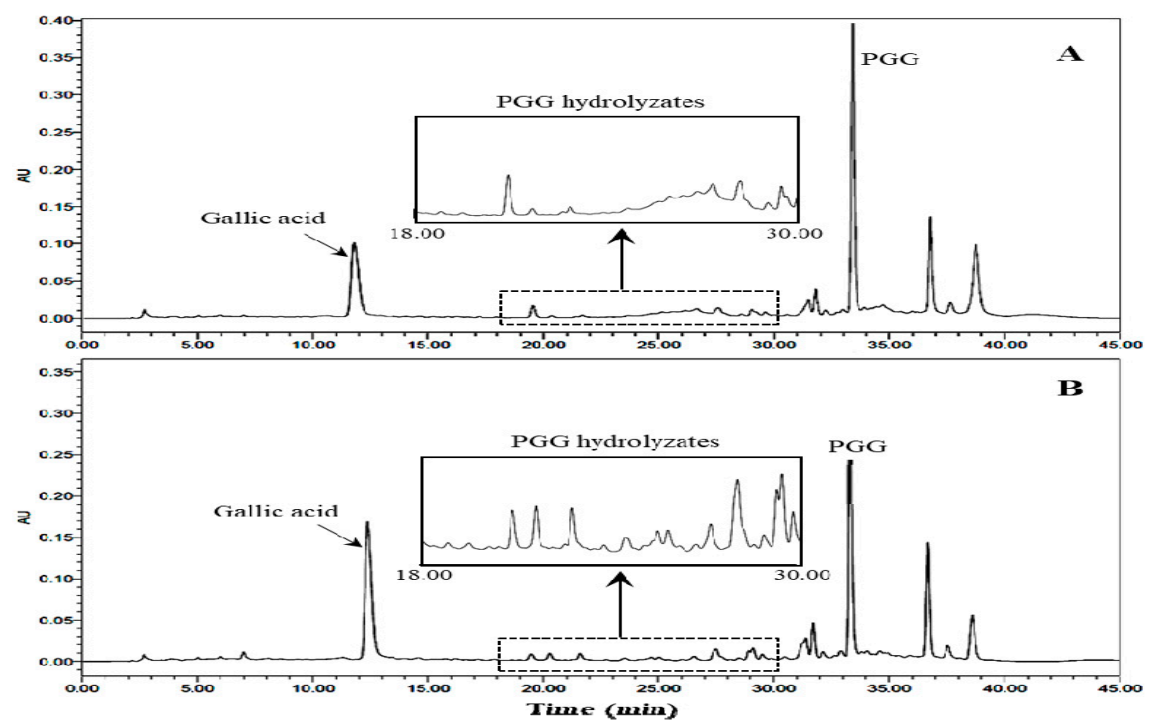

Figure 5. HPLC profiles (at $310 \mathrm{~nm}$ ) of $80 \%$ methanol extracts of the unfermented Toxicodendron vernicifluum stem bark (UTVSB) (A) and 10-day fermented TVSB (B).

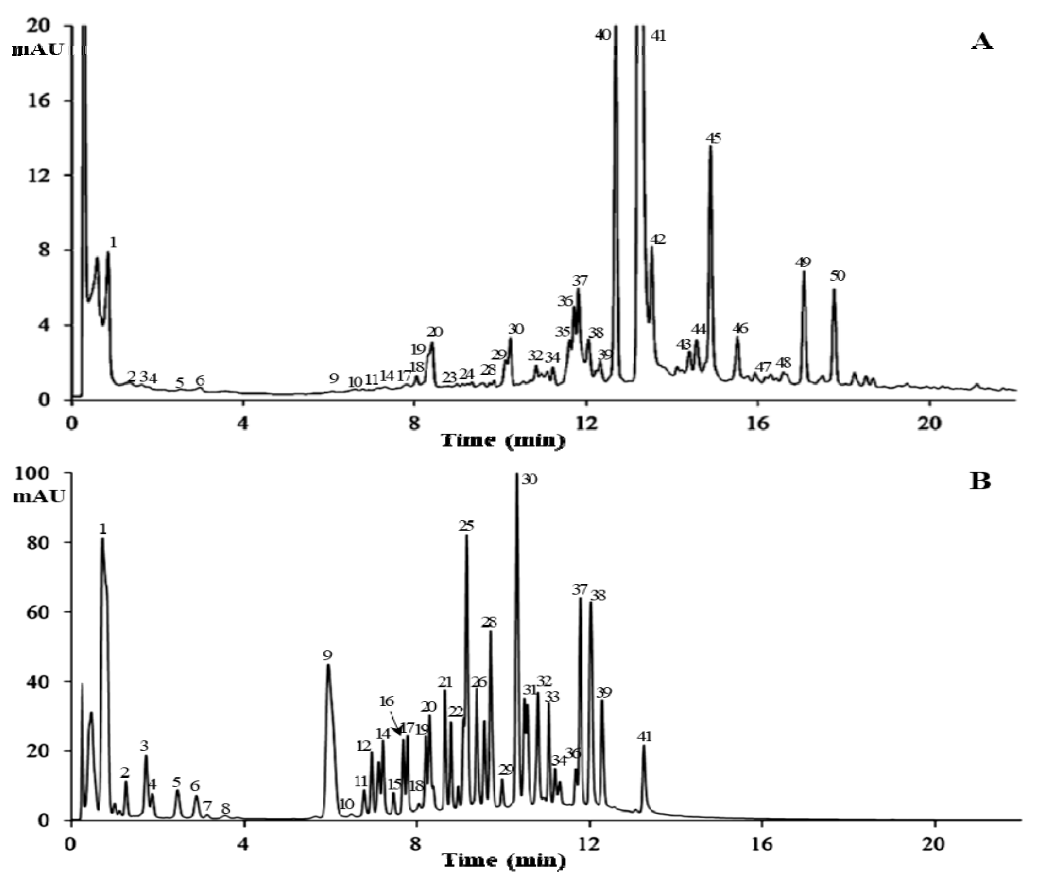

Figure 6. Total ion current (TIC) chromatograms of 10-day fermented TVSB (A) and PGG hydrolysate (B) by a crude enzyme preparation isolated from fermented TVSB. 
The peak 1 at 0.714 min was identified as gallic acid based on a quasimolecular ion at $m / z 169.0$ $[\mathrm{M}-\mathrm{H}]^{-}$. Peaks 2 and 4 , which were detected in both samples, showed the same quasimolecular ions at $m / z 331.1[\mathrm{M}-\mathrm{H}]^{-}$in the negative electrospray ionization mass spectrometry (ESI-MS) spectra and $\lambda_{\max }$ at $276 \mathrm{~nm}$. These compounds possessed one hexosyl moiety (162 amu) more than the fragment of peak 1 (gallic acid). Thus, these compounds were characterized as monogalloylglucose (MGG) isomers. Thirteen isomers (peaks 3, 5, 6, 11, 12, 13, 16, 17, and 19-23) detected in fermented TVSB showed a quasimolecular ion at $483.1[\mathrm{M}-\mathrm{H}]^{-}$with $\lambda_{\max }$ at $273-276 \mathrm{~nm}$.

Table 1. Compounds detected in fermented TVSB and PGG hydrolysate by crude enzyme preparation isolated from fermented TVSB.

\begin{tabular}{|c|c|c|c|c|c|c|c|}
\hline \multirow{2}{*}{$\begin{array}{c}\text { Peak } \\
\text { No. }\end{array}$} & \multirow{2}{*}{$\begin{array}{c}\mathrm{tR} \\
(\mathrm{min})\end{array}$} & \multirow{2}{*}{$\begin{array}{c}\mathrm{UV} \\
\left(\lambda_{\max }, \mathrm{nm}\right)\end{array}$} & \multirow{2}{*}{$\begin{array}{c}{[\mathbf{M}-\mathbf{H}]^{-}} \\
(m / z)\end{array}$} & \multirow{2}{*}{$\begin{array}{l}\text { Other Fragment } \\
\qquad(\mathrm{m} / \mathrm{z})\end{array}$} & \multirow{2}{*}{ Identification } & \multicolumn{2}{|c|}{ Detection } \\
\hline & & & & & & FTVSB & PGGH \\
\hline 1 & 0.714 & 272 & 169.0 & 331.1 & Gallic acid & $\mathrm{O}$ & $X$ \\
\hline 2 & 1.264 & 276 & 331.1 & $445.1,271.0$ & MGG & $\mathrm{O}$ & $\mathrm{O}$ \\
\hline 3 & 1.699 & 276 & 483.1 & $597.0,224.9$ & DGG & $\mathrm{O}$ & $\mathrm{O}$ \\
\hline 4 & 1.890 & 276 & 331.1 & $445.1,270.9$ & MGG (isomer) & $\mathrm{O}$ & $\mathrm{O}$ \\
\hline 5 & 2.371 & 276 & 483.1 & 597.0 & DGG (isomer) & $\mathrm{O}$ & $\mathrm{O}$ \\
\hline 6 & 2.781 & 273 & 483.1 & $181.0,597.0$ & DGG (isomer) & $\mathrm{O}$ & $\mathrm{O}$ \\
\hline 7 & 3.141 & & 255.1 & 123.0 & Unidentified & $X$ & $\mathrm{O}$ \\
\hline 8 & 3.500 & & 301.0 & $415.0,197.8$ & Unidentified & $\mathrm{O}$ & $\mathrm{O}$ \\
\hline 9 & 5.848 & 276 & 183.1 & 375.1 & Methyl gallate & $\mathrm{O}$ & $\mathrm{O}$ \\
\hline 10 & 6.464 & & 283.0 & 396.8 & Unidentified & $\mathrm{O}$ & $\mathrm{O}$ \\
\hline 11 & 6.744 & 276 & 483.1 & $241.0,596.9$ & DGG (isomer) & $\mathrm{O}$ & $\mathrm{O}$ \\
\hline 12 & 6.950 & 275 & 483.1 & $597.1,241.1$ & DGG (isomer) & $x$ & $\mathrm{O}$ \\
\hline 13 & 7.118 & 273 & 483.1 & $597.0,241.0$ & DGG (isomer) & $\mathrm{O}$ & $\mathrm{O}$ \\
\hline 14 & 7.234 & 276 & 225.1 & $483.1,339.0$ & Unidentified & $\mathrm{O}$ & $\mathrm{O}$ \\
\hline 15 & 7.449 & & 283.1 & $397.0,575.0$ & Unidentified & $X$ & $\mathrm{O}$ \\
\hline 16 & 7.692 & 275 & 483.1 & $241.1,597.0$ & DGG (isomer) & $X$ & $\mathrm{O}$ \\
\hline 17 & 7.799 & 275 & 483.1 & $597.0,241.1$ & DGG (isomer) & $\mathrm{O}$ & $\mathrm{O}$ \\
\hline 18 & 7.991 & & 283.1 & 397.1 & Unidentified & $\mathrm{O}$ & $\mathrm{O}$ \\
\hline 19 & 8.215 & 277 & 483.1 & $241.0,597.0$ & DGG (isomer) & $\mathrm{O}$ & $\mathrm{O}$ \\
\hline 20 & 8.313 & 277 & 483.1 & $597.0,241.1$ & DGG (isomer) & $\mathrm{O}$ & $\mathrm{O}$ \\
\hline 21 & 8.658 & 216,273 & 483.1 & $597.1,241.0$ & DGG (isomer) & $X$ & $\mathrm{O}$ \\
\hline 22 & 8.803 & 216,273 & 483.2 & $597.0,295.0$ & DGG (isomer) & $x$ & $\mathrm{O}$ \\
\hline 23 & 8.962 & 275 & 483.2 & $597.1,241.0$ & DGG (isomer) & $\mathrm{O}$ & $\mathrm{O}$ \\
\hline 24 & 9.097 & 276 & 635.1 & 749.1, 317.1 & TGG & $\mathrm{O}$ & $\mathrm{O}$ \\
\hline 25 & 9.111 & 216,279 & 431.2 & $499.1,563.1$ & Unidentified & $X$ & $\mathrm{O}$ \\
\hline 26 & 9.386 & 216,276 & 635.1 & $749.1,317.2$ & TGG (isomer) & $\mathrm{O}$ & $\mathrm{O}$ \\
\hline 27 & 9.578 & 217,276 & 635.1 & 317.1 & TGG (isomer) & $\mathrm{O}$ & $\mathrm{O}$ \\
\hline 28 & 9.708 & 216,276 & 635.1 & $749.1,317.1$ & TGG (isomer) & $\mathrm{O}$ & $\mathrm{O}$ \\
\hline 29 & 9.979 & 216,276 & 635.1 & $317.0,169.0$ & TGG (isomer) & $\mathrm{O}$ & $\mathrm{O}$ \\
\hline 30 & 10.315 & 217,278 & 635.1 & $317.1,169.0$ & TGG (isomer) & $\mathrm{O}$ & $\mathrm{O}$ \\
\hline 31 & 10.502 & 217,278 & 635.1 & 317.2 & TGG (isomer) & $\mathrm{O}$ & $\mathrm{O}$ \\
\hline 32 & 10.777 & 217,278 & 787.1 & $635.1,393.1$ & TeGG & $\mathrm{O}$ & $\mathrm{O}$ \\
\hline 33 & 11.057 & 217,278 & 635.1 & $317.1,749.1$ & TGG (isomer) & $\mathrm{O}$ & $\mathrm{O}$ \\
\hline 34 & 11.225 & 218,277 & 787.1 & $393.2,309.0$ & TeGG (isomer) & $\mathrm{O}$ & $\mathrm{O}$ \\
\hline 35 & 11.328 & 217,278 & 635.1 & $317.2,749.0$ & TGG (isomer) & $X$ & $\mathrm{O}$ \\
\hline 36 & 11.688 & 217,238 & 301.0 & 610.9 & Ellagic acid & $\mathrm{O}$ & $\mathrm{O}$ \\
\hline 37 & 11.790 & 217,278 & 787.1 & $393.2,301.1$ & TeGG (isomer) & $\mathrm{O}$ & $\mathrm{O}$ \\
\hline 38 & 12.005 & 217,279 & 787.1 & 393.2 & TeGG (isomer) & $\mathrm{O}$ & $\mathrm{O}$ \\
\hline 39 & 12.280 & 217,279 & 787.1 & 393.1 & TeGG (isomer) & $\mathrm{O}$ & $\mathrm{O}$ \\
\hline 40 & 13.195 & 217,279 & 787.1 & 393.1 & TeGG (isomer) & $\mathrm{O}$ & $x$ \\
\hline 41 & 13.256 & 217,279 & 939.1 & 469.1 & PGG & $\mathrm{O}$ & $\mathrm{O}$ \\
\hline 42 & 13.503 & 316,360 & 285.1 & 113.0 & Fisetin & $\mathrm{O}$ & $x$ \\
\hline 43 & 14.344 & & 255.1 & 432.9 & Unidentified & $\mathrm{O}$ & $X$ \\
\hline 44 & 14.549 & & 401.0 & $287.2,723.4$ & Unidentified & $\mathrm{O}$ & $X$ \\
\hline 45 & 14.806 & & 209.1 & 539.1 & Unidentified & $\mathrm{O}$ & $X$ \\
\hline 46 & 15.441 & 265,264 & 301.1 & $415.1,603.0$ & Quercetin & $\mathrm{O}$ & $X$ \\
\hline 47 & 16.430 & & 423.1 & $271.1,536.9$ & Unidentified & $\mathrm{O}$ & $X$ \\
\hline 48 & 16.995 & 261,379 & 271.1 & $551.1,385.1$ & Butein & $\mathrm{O}$ & $X$ \\
\hline 49 & 21.014 & & 417.1 & 531.0 & Unidentified & $\mathrm{O}$ & $X$ \\
\hline 50 & 23.105 & & 653.0 & $539.0,518.7$ & Unidentified & $\mathrm{O}$ & $X$ \\
\hline
\end{tabular}

DGG: digalloylglucose; FTVSB, 10-days fermented TVSB; MGG: monogalloylglucose; PGGH, PGG hydrolysate; O, detected; TeGG: tetragalloylglucose; TGG: trigalloylglucose; $X$, not detected. 
These compounds possessed one galloyl moiety (152 amu) more than monogalloylglucose. Accordingly, these compounds were tentatively characterized as digalloylglucose (DGG) isomers. In a similar manner, nine isomers (peaks 24, 26-31, 33, and 35) showed quasimolecular ions at $m / z$ $635.1[\mathrm{M}-\mathrm{H}]^{-}$and similar UV profiles. They possessed one galloyl moiety (152 amu) more than DGG. These compounds were characterized as trigalloylglucose (TGG) isomers. Six isomers at peaks 32, 34, and 37-40 were also suggested as tetragalloylglucose (TeGG) isomers by their quasimolecular ion at $m / z 787.1[\mathrm{M}-\mathrm{H}]^{-}$and UV profiles $\left(\lambda_{\max }\right.$ at $\left.273-276 \mathrm{~nm}\right)$. The mass spectra of oligomeric galloylglucoses that were identified in both samples are presented in Figure 7.

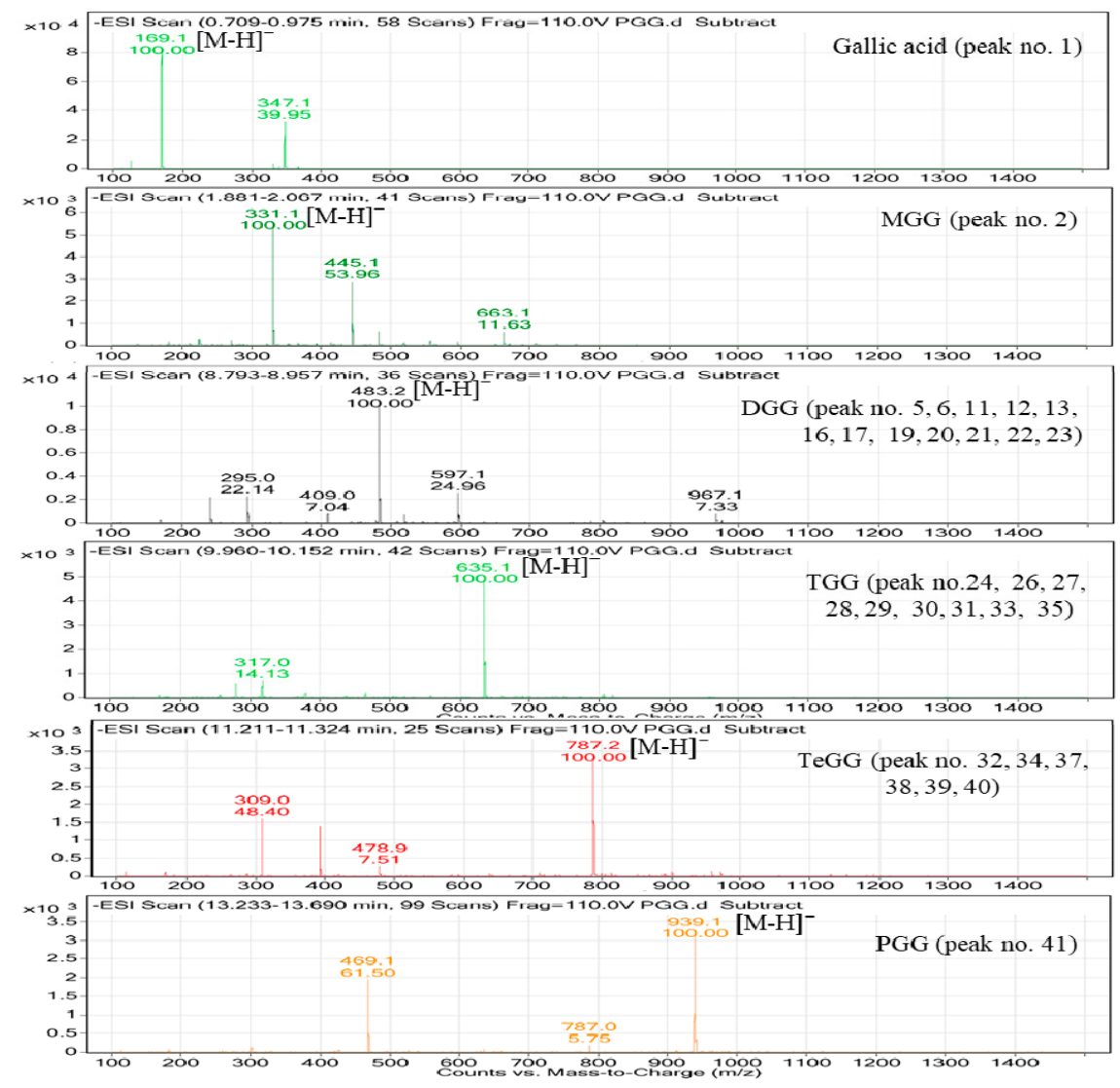

Figure 7. LC-MS spectra of PGG and its hydrolysates identified in fermented TVSB.

Some of these PGG hydrolysates have been previously found in Euvcalyptus nitens wood [35], mango [36], Rhus coriaria [37], Psidium guineense, Syzygium cumini, Pouteria macrophylla [38], and the degradation products of tannin by Aspergillus niger [39]. These compounds can affect the expression of biological activities of target plants. In addition, galloylglucose oligomers may have more potent antioxidant activities than PGG or ascorbic acid [40]. Generally, microbial tannase (E.C.3.1.1.20) hydrolyses the ester and depside bonds of gallotannins and PGG to produce gallic acid and methyl gallate as end products $[41,42]$. However, the PGG-degrading enzyme from $F$. fraxinea in this study catalyzed the hydrolysis of the bonds that were present in the molecules of PGG to produce oligomeric galloylglucoses-mainly DGG, TGG, and TeGG-instead of gallic acid. In addition, peak 36 was tentatively identified as ellagic acid based on its quasimolecular ion at $301.0[\mathrm{M}-\mathrm{H}]^{-}$and its UV profile. Peaks 42, 46, and 48 with quasimolecular ions $[\mathrm{M}-\mathrm{H}]^{-}$of $m / z 285.1, m / z 301.1$, and $m / z 271.1$ were identified as fisetin, quercetin, and butein, respectively. These compounds have been previously reported as the major bioactive components of T. vernicifluum [24,25]. 


\subsection{Changes of Antioxidant Activities}

Due to the differences in the theoretical bases of different antioxidant measurements, a single antioxidant property model can hardly reflect the antioxidant capacity of the samples [43]. For this reason, three model systems, i.e., 2,2-diphenyl-1-picrylhydrazyl (DPPH) radical scavenging activity, 2,2'-azino-bis(3-ethylbenzothiazoline-6- sulfonic acid) (ABTS) radical scavenging activity, and ferric reducing/antioxidant power (FRAP) were used to evaluate the antioxidant properties of fermented TVSB. DPPH and ABTS rely on the reaction of radicals and cation radicals, respectively, and the FRAP method relies on the reduction by the antioxidant components of complex ferric ion-TPTZ (2,4,6-tri(2-pyridyl)-s-triazine). A study by Gorinstein et al. [44] observed a high correlation of antioxidant capacities measured by ABTS, DPPH, and FRAP assays in some fruits, while Pellegrini et al. [45] reported a weak correlation on antioxidant capacity measured by FRAP and ABTS assays in some vegetables and beverages. The results of changes in antioxidant capacities are presented in Figure 8. DPPH radical scavenging activity rapidly decreased from $82.45 \pm 1.41 \%$ in unfermented TVSB (day 0 ) to $21.31 \pm 1.35 \%$ after nine days and $15.88 \pm 0.85 \%$ after 12 days of fermentation, while no significant change was observed thereafter until 22 days. The antioxidant properties of T. vernicifluum stem and bark can be explained by the higher contents of phenolic compounds such as fustin, fisetin, sulfuretin, quercetin, gallotannins, and urushiols [6,7].
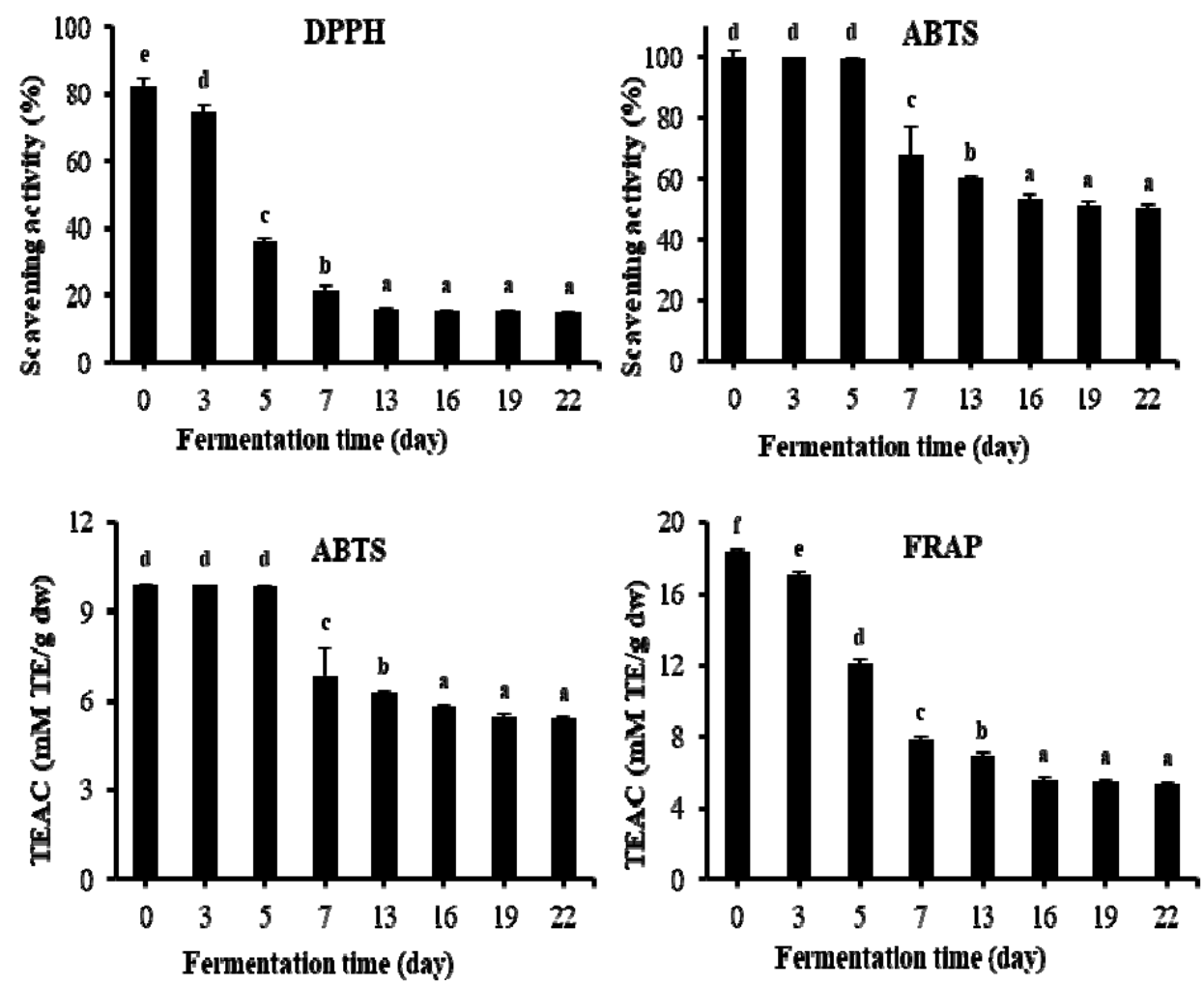

Figure 8. Changes of antioxidant activities during fermentation of TVSB by F. fraxinea. Different letters indicate values that are significantly different by Duncan's multiple range test at $5 \%$ level. TEAC, Trolox equivalent antioxidant capacity. DPPH, 2,2-diphenyl-1-picrylhydrazyl; ABTS, 2,2'-azino-bis-3-ethylbenzothiazoline-6-sulfonic acid; FRAP, ferric reducing antioxidant power. Error bars are the standard deviations of triplicate measurements.

ABTS radical scavenging activity as an inhibition percentage (\%) showed a significant decrease $(p<0.05)$ from $99.83 \pm 1.96 \%$ in the unfermented sample to $67.85 \pm 9.40 \%$ and $53.04 \pm 2.11 \%$ after nine and 15 days of fermentation, respectively. No meaningful change was observed thereafter until 22 days. Trolox equivalent antioxidant capacity (TEAC) is a method that provides information on the overall 
status of antioxidants within a test sample, and has proven to be a useful indicator for determining the ability of an organism to mitigate the potential damage caused by reactive oxygen species. It has been widely used for studying the antioxidant capacity of phytochemicals and biological samples [46]. In this study, the TEAC value also decreased from $9.89 \pm 0.06 \mathrm{mM} \mathrm{TE} / \mathrm{g}$ DW in the unfermented sample to $6.82 \pm 0.03 \mathrm{mM}$ TE/g DW (31\% decrease) and $6.29 \pm 0.03 \mathrm{mM} \mathrm{TE} / \mathrm{g}$ DW (36.4\% decrease) after nine and 15 days of fermentation, respectively, with no significant change until 22 days. Similarly, the FRAP value decreased significantly $(p<0.05)$ during the first 12 days of fermentation. It decreased by $57.3 \%$ (from $18.39 \pm 0.10$ to $7.85 \pm 0.21 \mathrm{mM} / \mathrm{g} \mathrm{DW}$ ), with no significant decrease observed thereafter until 22 days.

Phenolic compounds can be enzymatically oxidized and polymerized by polyphenol oxidases such as laccases or tyrosinases. Previous studies have reported that oxidized products, polymers, and aggregates exhibit stronger antioxidant activities than their corresponding monomeric flavonoids [34,47-49]. However, it can be clearly observed that fermented TVSB still retained antioxidant activities, although it was relatively weaker compared to that of UTVSB. Kim et al. [7] reported that the methanol and ethyl acetate fractions of fermented TVSB by F. fraxinea showed higher radical scavenging and reducing power activities than those of synthetic antioxidant butylated hydroxyanisole (BHA) and butylated hydroxytoluene (BHT). Therefore, fermented TVSB might be more preferable than the above synthetic antioxidant products. Oligomeric galloylglucoses that originated from PGG such as MGG, DGG, TGG, and TeGG may also have contributed to the antioxidant activities of fermented TVSB.

\section{Materials and Methods}

\subsection{Plant Material}

TVSB was collected from a 10-year-old tree that had been cultivated in Imsil-Gun, Chonbuk Province, Republic of Korea in October 2015. The plant material was authenticated by one of the authors (M.K. Kim). A voucher was deposited at the Fermentation Laboratory, Department of Food Science and Biotechnology, Chonbuk National University, Jeonju 54896, Jeonbuk, Republic of Korea. The fresh TVSB was air-dried $\left(60^{\circ} \mathrm{C}\right)$ for 24 hours and kept at room temperature $\left(20^{\circ} \mathrm{C}\right)$ until used for further experiments within one week.

\subsection{Chemicals}

Urushiol standards $\left(\mathrm{C}_{15: 3}, \mathrm{C}_{15: 2}, \mathrm{C}_{15: 1}\right)$ were purchased from Phytolab $\mathrm{GmbH}$ and $\mathrm{Co}$. (Dutendorfer Straße, Vestenbergsgreuth, Germany). Fustin, fisetin, sulfuretin, and butein were purchased from Chromadex Co. (Irvine, CA, USA). Gallic acid, methyl gallate, quercetin, taxifolin, PGG, Folin-Ciocalteu reagent, 2,2-diphenyl-1-picrylhydrazyl (DPPH), 2,2'-azino -bis(3-ethylbenzothiazoline-6-sulfonic acid), diammonium salt (ABTS), 6-hydroxy-2,5,7,8 -tetramethylchromane-2-carboxylic acid (Trolox), 2,4,6-tri(2-pyridyl)-s-triazine (TPTZ), potassium persulfate, tannic acid, bovine serum albumin (BSA), and sodium dodecyl sulfate (SDS) were purchased from Sigma-Aldrich (St. Louis, MO, USA). HPLC grade methanol, acetonitrile, and deionized water were purchased from J.T. Baker Co. (Phillipsburg, NJ, USA). All of the other reagents were of analytical grade.

\subsection{Microorganism and Culture Conditions}

The strain of Fomitella fraxinea (Bull.) Imazeki (KACC 42289) was kindly donated by the Korean Agricultural Culture Collection (KACC) of the Rural Development Administration (RDA), Wanju, Jeonbuk, Republic of Korea. 


\subsection{Fermentation of TVSB by F. fraxinea}

The strain was preincubated onto potato dextrose agar (Becton, Dickinson and Company, Sparks, MD, USA) for six days at $25{ }^{\circ} \mathrm{C}$. Sterilization of the culture media was performed at $121{ }^{\circ} \mathrm{C}$ for $30 \mathrm{~min}$. The preincubated strain was inoculated into germinated-malt medium (11 Brix $\left.{ }^{\circ}\right)$ saccharified at $65{ }^{\circ} \mathrm{C}$ with four-fold tap water $(v / v)$ for eight hours, and then cultured for two weeks at $25-26{ }^{\circ} \mathrm{C}$ with gentle shaking (120 rpm) using an orbital shaker (model SK-600, Jeiotech Co., LTD. Daejon, Korea). The air-dried TVSB of crushed coarse powder was placed in an Erlenmeyer flask $(500 \mathrm{~mL})$. The moisture content of each powdered sample $(100 \mathrm{~g})$ was then adjusted to approximately $65 \%$ with tap water. Each flask was sterilized at $121^{\circ} \mathrm{C}$ for $30 \mathrm{~min}$. The day-0 (control) sample was freeze-dried immediately and stored at $-20^{\circ} \mathrm{C}$ until further analysis. The remaining samples were inoculated with five $\mathrm{mL}$ of $F$. fraxinea liquid culture except for the unfermented (matched controls) and incubated at room temperature $\left(25-26^{\circ} \mathrm{C}\right)$ with gentle shaking $(120 \mathrm{rpm})$ for each required time frame before further analysis. All of the fermentations were set up on the same day, and each sample for the specific time point was retrieved with its matched control at the same time. Each sample was then freeze-dried at the end of each time frame and stored until use.

\subsection{Extraction and HPLC Analysis of Urushiols.}

\subsubsection{Extraction}

A powdered sample $(1.0 \mathrm{~g})$ of UTVSB and fermented TVSB was extracted twice with $20 \mathrm{~mL}$ of acetone in an ultrasonic bath (Hwa Shin Instrument Co., Ltd., Seoul, Korea) for $20 \mathrm{~min}$ at room temperature and centrifuged at $5000 \mathrm{rpm}$ for $15 \mathrm{~min}$. Supernatants were combined and concentrated under vacuum at $45^{\circ} \mathrm{C}$, and the residue was dissolved in acetone (five $\mathrm{mL}$ ).

\subsubsection{Thin-Layer Chromatography (TLC) Analysis}

TLC was carried out for the extracted samples as follows. The developing solvent was a mixture of chloroform-methanol-water (65:35:10, lower phase). The spots were detected either under UV $\left(254 \mathrm{~nm}\right.$ ) or by spraying a $10 \% \mathrm{CuSO}_{4}$ solution in an $8 \% \mathrm{H}_{2} \mathrm{SO}_{4}$ solution followed by heating at $110{ }^{\circ} \mathrm{C}$ for $10 \mathrm{~min}$.

\subsubsection{HPLC Analysis}

The standard stock solution of urushiols was prepared at a concentration of $1000 \mu \mathrm{g} / \mathrm{mL}$ in acetone. The stock solution was serially diluted with acetone to obtain a calibration curve at seven concentration levels $(10-500 \mu \mathrm{g} / \mathrm{mL})$ for $C_{15}$ and $C_{15: 1}$ and at 5-250 $\mu \mathrm{g} / \mathrm{mL}$ for $C_{15: 2}$. HPLC analysis was performed using an HPLC system (Waters, Milford, MA, USA) equipped with a 2690 separation module and 996 photodiode array (PDA) detector with a YMC-Pak Pro C18 column $(4.6 \mathrm{~mm} \times 250$ $\mathrm{mm}$, five $\mu \mathrm{m}$; YMC Co., LTD, Tokyo, Japan). The mobile phase was $90 \% \mathrm{MeOH}$ in deionized water at a flow rate of $1.0 \mathrm{~mL} / \mathrm{min}$ (isocratic) with an injection volume of $10 \mu \mathrm{L}$. The UV detection wavelength was set at $273 \mathrm{~nm}$. The concentration of each constituent was calculated using the calibration curve by plotting the peak area of the corresponding substance against the concentration (in $\mu \mathrm{g} / \mathrm{mL}$ ) of the standard substance.

\subsection{Extraction for Polyphenols and Gallotannins}

A powdered sample $(1.0 \mathrm{~g})$ of UTVSB and fermented TVSB was extracted twice with $20 \mathrm{~mL}$ of $80 \%$ aqueous $\mathrm{MeOH}$ using an ultrasonic bath for $30 \mathrm{~min}$ and centrifuged at $5000 \mathrm{rpm}$ for $15 \mathrm{~min}$. The supernatants was concentrated at $45^{\circ} \mathrm{C}$ under reduced pressure, and the residue was dissolved in $80 \%$ methanol (five $\mathrm{mL}$ ) for an analysis of total flavonoids, individual flavonoids, and gallotannins by HPLC, and for antioxidant activity assay. 


\subsection{Total Phenol}

The total phenolic content of the samples was determined according to a method described by Chandra et al. [50] with some modifications. Briefly, an $80 \% \mathrm{MeOH}$ extract $(20 \mu \mathrm{L})$ of each sample was mixed with a 50\% Folin-Ciocalteu phenol reagent $(20 \mu \mathrm{L})$ in 96-well plates. After five minutes, one $\mathrm{N}$ of sodium carbonate $(20 \mu \mathrm{L})$ was added to the mixture, and distilled water was added to reach a final volume of $200 \mu \mathrm{L}$. After incubation at room temperature in the dark for $30 \mathrm{~min}$, the absorbance of a test sample against a blank was measured at a wavelength of $725 \mathrm{~nm}$ using a VersaMax ELISA microplate leader (Molecular Devices, LLC, CA, USA). The phenolic content was calculated based on a calibration curve of gallic acid. The result was expressed as mg of gallic acid equivalent (GAE) per $100 \mathrm{~g}$ of the dried sample.

\subsection{Total Flavonoid}

The total flavonoid content was measured according to a method described by Zhishen et al. [51] with some modifications. Briefly, an $80 \% \mathrm{MeOH}$ extract $(30 \mu \mathrm{L})$ of each sample was mixed with $30 \mu \mathrm{L}$ of $5 \%$ sodium nitrite solution. After five minutes of reaction, $300 \mu \mathrm{L}$ of $5 \%$ aluminum chloride was added. Then, $200 \mu \mathrm{L}$ of one $\mathrm{N}$ of $\mathrm{NaOH}$ was added six minutes later, and the total volume was adjusted to one $\mathrm{mL}$ with distilled water. The absorbance of the test sample against a blank was measured at a wavelength of $510 \mathrm{~nm}$ with a Shimadzu UV-1601 spectrophotometer (Kyoto, Japan). The flavonoid content was calculated using a calibration curve of rutin. The result was expressed as mg rutin equivalent (RE) per $100 \mathrm{~g}$ of the dried sample.

\subsection{HPLC Analysis of Individual Flavonoids}

The stock solution was serially diluted with methanol to obtain seven concentration levels $(12.5-750 \mu \mathrm{g} / \mathrm{mL})$ for each analyte to prepare a calibration curve. HPLC analysis was performed using an HPLC system (Waters, Milford, MA, USA) equipped with a 2690 separation module and a 996 photodiode array (PDA) detector with a ZORBAX Eclipse XDB C18 column $(4.6 \mathrm{~mm} \times 250 \mathrm{~mm}$, five $\mu \mathrm{m}$; Agilent Technologies, Technologies, Inc., Santa Clara, CA, USA). The mobile phase was $0.1 \%$ formic acid in ionized water (A) and 90\% acetonitrile in water (B). The ratio of the mobile phase was A:B mixed at 90:10 (zero to one minute), 20:80 (one to $15 \mathrm{~min}$ ), and 90:10 (15-25 min) at a flow rate of $1.0 \mathrm{~mL} / \mathrm{min}$. The UV detection wavelength was set at $280 \mathrm{~nm}$. The concentration of each constituent was calculated using a calibration curve by plotting the peak area of the corresponding substance against the concentration $(\mu \mathrm{g} / \mathrm{mL})$ of the standard substance.

\subsection{Hydrolysis of PGG by Tannases}

\subsubsection{Preparation of PGG}

PGG was prepared from tannic acid according to the method of Chen and Hagerman [52] with slight modification. A sample of $5.0 \mathrm{~g}$ of tannic acid was methanolyzed in $100 \mathrm{~mL}$ of $70 \%$ aqueous methanol in $0.1 \mathrm{M}$ of sodium acetate $\left(\mathrm{pH} 5.00\right.$ at $65{ }^{\circ} \mathrm{C}$ ) After methanolysis for $15 \mathrm{~h}$, the $\mathrm{pH}$ of the reaction mixture was adjusted to 6.0, and methanol was removed by evaporation under reduced pressure below $35{ }^{\circ} \mathrm{C}$. Water was added to maintain the volume, replacing evaporated methanol. The resulting aqueous solution was sequentially extracted with three volumes of diethyl ether and ethyl acetate. The ethyl acetate fraction was combined and evaporated under reduced pressure, and then, distilled water was added to the ethyl acetate extract. The resulting milky suspension was centrifuged for $15 \mathrm{~min}$ at $4500 \mathrm{rpm}$ (model VS-550, Vision Scientific Co., LTD, Daejon, Korea). The precipitate containing PGG was washed twice with $20 \mathrm{~mL}$ of ice-cold $2 \%$ aqueous methanol. In the last step, the final material was obtained by freeze-drying. The material obtained was identified as PGG by LC-MS and NMR spectroscopy (JEOL JNM-ECA 600 FT-NMR, Akishima, Tokyo, Japan) as follows: UV, $\lambda_{\max } 280 \mathrm{~nm}$ (methanol); ESI-LC-MS, $m / z 939.2[\mathrm{M}-\mathrm{H}]^{-}\left(\mathrm{C}_{41} \mathrm{H}_{32} \mathrm{O}_{26}\right) ;{ }^{1} \mathrm{H}-\mathrm{NMR}$ $\left(600 \mathrm{MHz}\right.$, methanol- $\left.d_{4}\right), \delta 7.01(2 \mathrm{H}, \mathrm{s}), 6.95(2 \mathrm{H}, \mathrm{s}), 6.87(2 \mathrm{H}, \mathrm{s}), 6.84(2 \mathrm{H}, \mathrm{s}), 6.79(2 \mathrm{H}, \mathrm{s}), 6.13(1 \mathrm{H}, \mathrm{d}$, 
$J=8.25 \mathrm{~Hz}), 5.81(1 \mathrm{H}, \mathrm{t}, J=9.62 \mathrm{~Hz}), 5.51(1 \mathrm{H} . \mathrm{dd}, J=9.62 \mathrm{~Hz}), 5.50(1 \mathrm{H}, \mathrm{t}, J=9.62 \mathrm{~Hz}), 4.42(1 \mathrm{H}, \mathrm{d}$, $J=11.68 \mathrm{~Hz}), 4.30(2 \mathrm{H}, \mathrm{m}) ;{ }^{13} \mathrm{C}-\mathrm{NMR}\left(150 \mathrm{~Hz}\right.$, methanol- $\left.d_{4}\right), \delta 168.05,167.41,167.14,167.04,166.33$, 146.66 (x2), 146.58, 146.54, 146.48, 146.39, 140.87, 140.47 (x2) 140.41(x2), 140.24 (x2), 140.12 (x2), 121.15, $120.47,120.34,120.31,119.84,110.73(x 2), 110.57(x 2), 110.51(x 2), 110.48(x 2), 110.44(x 2), 93.93,74.53$, $74.22,72.30,69.91,63.22$.

\subsubsection{Preparation of Crude Enzymes from Fermented TVSB}

All of the procedures for the preparation of crude enzyme were carried out at $4{ }^{\circ} \mathrm{C}$ unless otherwise indicated. TVSB $(50 \mathrm{~g})$ that had been fermented for 10 days with F. fraxinea was mixed with $500 \mathrm{~mL}$ of $0.1 \mathrm{M}$ of sodium phosphate buffer ( $\mathrm{pH}$ 5.5) with gentle stirring for four hours, and then homogenized with an Omni mixer homogenizer (Omni International, Kennesaw, GA, USA) for one minute. The homogenate was squeezed through a cheese cloth, and the filtrate was centrifuged at $10000 \times g$ for $20 \mathrm{~min}$. The crude enzyme containing tannase was prepared by solid ammonium sulfate $(30-80 \%)$ saturation. After centrifugation at $10000 \times g$ for $20 \mathrm{~min}$, the precipitate was dissolved in $10 \mathrm{mM}$ of sodium acetate buffer ( $\mathrm{pH}$ 5.5). After dialysis for 24 hours, the solution was centrifuged at $10000 \times g$ for $20 \mathrm{~min}$, and the supernatant was lyophilized.

\subsubsection{Tannase Assay}

Lyophilized crude enzyme preparation (50 mg) was dissolved in $10 \mathrm{~mL}$ of $0.1 \mathrm{M}$ of sodium acetate buffer ( $\mathrm{pH}$ 5.5). Tannase activity was measured using the method of Mondal et al. [53] with modifications. Briefly, the solution $(150 \mu \mathrm{L})$ containing three $\mathrm{mM}$ of tannic acid $(0.2 \mathrm{M}$ of acetate buffer, $\mathrm{pH}$ 5.5) as a substrate was added to $200 \mu \mathrm{L}$ of crude enzyme, and the reaction solution was incubated at $40{ }^{\circ} \mathrm{C}$ for $30 \mathrm{~min}$. Subsequently, a BSA solution $(1 \mathrm{mg} / \mathrm{mL})$ was added to the flask and then kept at room temperature for $15 \mathrm{~min}$. The reaction solution was centrifuged ( $5000 \mathrm{rpm}, 20 \mathrm{~min}$ ) to remove the supernatant, and $1.5 \mathrm{~mL}$ of SDS-triethanolamine solution was added to the precipitate. To stabilize the color, $0.5 \mathrm{~mL}$ of $0.16 \% \mathrm{FeCl}_{2}(0.01 \mathrm{~N} \mathrm{HCl})$ was added, and the mixture was allowed to stand at room temperature for $15 \mathrm{~min}$. Its absorbance was then measured at a wavelength of $530 \mathrm{~nm}$. The calibration curve was prepared using tannic acid under the same conditions. One unit ( $U$ ) of tannase was defined as the amount of enzyme that was required to hydrolyze $1.0 \mu \mathrm{M}$ of tannic acid per minute under specified conditions.

\subsubsection{Enzymatic Hydrolysis of PGG}

The reaction mixture $(50 \mathrm{~mL})$ containing $0.5 \mathrm{~g}$ of PGG in $2.5 \mathrm{~mL}$ of methanol and crude enzyme preparation (30-80\% ammonium sulfate precipitate) isolated from fermented TVSB or Asp. oryzae tannase containing $30 \mathrm{U}$ of tannase activity in $47.5 \mathrm{~mL}$ of $0.1 \mathrm{M}$ sodium acetate buffer (pH 5.5) were incubated for 12 hours at $45^{\circ} \mathrm{C}$ with gentle shaking. After the reaction mixture was kept in a boiling water bath for $10 \mathrm{~min}$, it was subjected to HPLC and LC-MS analysis.

\subsection{Analysis of PGG Hydrolysates in Fermented TVSB}

\subsubsection{HPLC}

The standard solution was serially diluted with $80 \%$ methanol to obtain seven concentration levels $(12.5-750 \mu \mathrm{g} / \mathrm{mL})$ for each compound to prepare a calibration curve. HPLC analysis was performed using an HPLC system equipped with a 2690 separation module and a 996 photodiode array (PDA) detector with a ZORBAX Eclipse XDB- $\mathrm{C}_{18}$ column. The mobile phase consisted of $0.1 \%$ formic acid in ionized water (A) and $90 \%$ acetonitrile in water (B). The ratio of $\mathrm{A}: \mathrm{B}$ as the mobile phase was maintained at 95:5 (zero to two minutes), 45:55 (two to $25 \mathrm{~min}$ ), 40:60 (25 to $30 \mathrm{~min}$ ), and 95:5 (30 to $40 \mathrm{~min}$ ) at a flow rate of $0.8 \mathrm{~mL} / \mathrm{min}$. The UV detection wavelength was set at $310 \mathrm{~nm}$. 


\subsubsection{HPLC-MS}

The powder of fermented TVSB $(1.0 \mathrm{~g})$ was extracted with $20 \mathrm{~mL}$ of acetone in an ultrasonic bath (Hwa Shin Instrument Co., Ltd., Seoul, Korea) for $20 \mathrm{~min}$ at room temperature and centrifuged at $4500 \mathrm{rpm}$ for $20 \mathrm{~min}$. The residue was extracted one more time using the same solvent. The supernatant was concentrated under vacuum at $45{ }^{\circ} \mathrm{C}$, and the residue was dissolved in five $\mathrm{mL}$ of acetone. A standard stock solution of urushiols was prepared at a concentration of $1000 \mu \mathrm{g} / \mathrm{mL}$ in acetone. The stock solution was serially diluted with acetone to obtain a calibration curve at seven concentration levels $(10-500 \mu \mathrm{g} / \mathrm{mL})$ for $\mathrm{C}_{15}$ and $\mathrm{C}_{15: 1}$, and at 5-250 $\mu \mathrm{g} / \mathrm{mL}$ for $\mathrm{C}_{15: 2}$.

HPLC-MS analysis was performed on an Agilent chromatographic system 1100 series (Agilent Technologies, Santa Clara, CA, USA) equipped with a G1379A degasser, a G1312A binary pump, a 1329A autosampler, and a G1316A column thermostat. The LC was coupled with an Agilent ion trap 1100 SL mass detector. Separation was performed using a reverse phase column Kinetex $C_{18}(50 \times 2.1$ $\mathrm{mm}$ i. d., $2.6 \mu \mathrm{m}$, Phenomenex, Torrance, CA, USA). The mobile phase consisted of $0.1 \%$ formic acid in water (A) and $0.1 \%$ formic acid in $90 \%$ acetonitrile with the following gradient program: zero to four minutes, $90 \%$ A; four to $25 \mathrm{~min}, 90-40 \% \mathrm{~A} ; 25$ to $30 \mathrm{~min}, 40-90 \% \mathrm{~A}$; and 30 to $35 \mathrm{~min}, 90 \% \mathrm{~A}$. The flow rate was set at $0.5 \mathrm{~mL} / \mathrm{min}$, and the temperature was set at $40^{\circ} \mathrm{C}$. The injection volume was two $\mu \mathrm{L}$. The MS was equipped with an electrospray ionization (ESI) interface in negative ion mode. The ESI parameters were set as follows: ion source temperature, $350{ }^{\circ} \mathrm{C}$; gas flow rate (nitrogen), $15 \mathrm{~L} / \mathrm{min}$; nebulizer pressure, 40 psi pressure; capillary voltage, $3000 \mathrm{~V}$; fragmentation voltage, $400 \mathrm{~V}$; collision energy, $0 \mathrm{~V}$; and full-scan data acquisition, $50-1200 \mathrm{~m} / \mathrm{z}$.

\subsection{Antioxidant Activity}

\subsubsection{DPPH Free Radical Scavenging Activity}

The DPPH radical scavenging activity of the sample was determined according to the method described by Thaipong et al. [54] with some modifications. Briefly, the extract $(20 \mu \mathrm{L})$ was added to an $80-\mu \mathrm{L}$ DPPH solution $(500 \mu \mathrm{M})$ and $100-\mu \mathrm{L}$ Tris-HCl buffer $(0.1 \mathrm{M})$. The mixture was incubated at room temperature in the dark for $20 \mathrm{~min}$. As a blank, the test was repeated using a buffer instead of a sample. Absorbance was measured at a wavelength of $517 \mathrm{~nm}$ using a microplate leader, and the scavenging activity of the extract was calculated against a blank as follows.

$$
\text { DPPH radical scavenging activity }(\%)=\left(1-\mathrm{A}_{0} / \mathrm{A}_{1}\right) \times 100
$$

where $A_{0}$ and $A_{1}$ are the absorbance values of the test sample and control, respectively.

\subsubsection{ABTS Free Radical Scavenging Activity}

ABTS free radical scavenging activity was determined by the methods described by Thaipong et al. [54] with some modifications. Briefly, a mixture of ABTS (7.4 mM) solution and potassium persulfate $(2.6 \mathrm{mM})$ solution in equal volumes was kept for 12 hours at room temperature in a dark to form an ABTS cation. The solution was diluted by mixing with methanol to obtain an absorbance of $1.0 \pm 0.02$ at $734 \mathrm{~nm}$ using a UV-Vis spectrophotometer. Then, $100 \mu \mathrm{L}$ of the extract was added to $1400 \mu \mathrm{L}$ of the diluted ABTS solution, and the mixture was incubated at room temperature for one hour in the dark. After the reaction, its absorbance was measured at a wavelength of $734 \mathrm{~nm}$. The calibration curve was linear between $25-400 \mu \mathrm{M}$ Trolox. Results were expressed as $\mu \mathrm{M}$ Trolox equivalent (TE) g dry weight, and the ABTS radical scavenging activity (\%) was also calculated with the following equation:

$$
\text { ABTS radical scavenging activity }(\%)=\left(1-\mathrm{A}_{0} / \mathrm{A}_{1}\right) \times 100
$$

where $\mathrm{A}_{0}$ and $\mathrm{A}_{1}$ are the absorbance values of the test sample and control, respectively. 


\subsubsection{Ferric Reducing/Antioxidant Power (FRAP)}

Ferric reducing power was determined using FRAP assay [55] with some modification. The working solution for FRAP assay was prepared by mixing 10 volumes of $300 \mathrm{mM}$ of acetate buffer, $\mathrm{pH} 3.6$, with one volume of $10 \mathrm{mM}$ of TPTZ in $40 \mathrm{mM}$ of $\mathrm{HCl}$, and with one volume of $20 \mathrm{mM}$ of ferric chloride. All of the required solutions were freshly prepared before their uses. A sample extract $(80 \mu \mathrm{L})$ was added to $1420 \mu \mathrm{L}$ of FRAP reagent. The reaction mixture was incubated at room temperature for $30 \mathrm{~min}$ in the dark. Then, the absorbance of the samples was measured at $593 \mathrm{~nm}$. The calibration curve was linear between 25-600 $\mu \mathrm{M}$ Trolox. Results were expressed as $\mu \mathrm{M}$ Trolox equivalent (TE)/g dry weight.

\subsection{Statistical Analysis}

All of the experiments were performed in triplicate. All of the values were expressed as mean \pm standard deviation (SD). All of the statistical analyses were performed with SPSS (ver. 10.1) for Windows. One-way analysis of variance (ANOVA) and Duncan's multiple range test was carried out to test any significant difference among various treatments. Significant differences were determined at $p<0.05$.

\section{Conclusions}

Dynamic changes in urushiol congeners, polyphenols, gallotannins, and antioxidant activities during the fermentation of TVSB by mushroom $F$. fraxinea to reduce or detoxify urushiols were investigated. The content of urushiol congeners noticeably decreased within 10 days of fermentation with a slow decrease thereafter until 22 days. The contents of total phenol, total flavonoid, and individual flavonoids also decreased in similar patterns as those of the urushiols. PGG was hydrolyzed during the fermentation process, resulting in the formation of a number of oligomeric galloylglucoses isomers. These results indicate that PGG was mainly hydrolyzed into oligomeric galloylglucoses (TeGG, TGG, DGG, and MGG) by tannin-hydrolyzing enzymes secreted from F. fraxinea mycelia during fermentation. The overall decrease in antioxidant activity during the fermentation of TVSB may be associated with a decrease in phenolic compounds. Nonetheless, the fermented TVSB has to some extent retained strong antioxidant activity, although it is relatively weaker than that of UTVSB. Oligomeric galloylglucoses such as MGG, DGG, TGG, and TeGG, which originated from PGG may also have contributed to the antioxidant activity of fermented TVSB. Although TVSB extracts are fermented for 20-28 days using F. fraxinea to be marketed as functional food raw materials in Korea, the present study suggests that the optimal fermentation period to remove or reduce toxic urushiols is between 13-16 days, with a minimized reduction of useful constituents such as flavonoids and gallotannins. The findings in the present work also provide clear evidence for the need of additional studies on the enzymatic characteristics of PGG-hydrolyzing enzymes secreted from $F$. fraxinea during the fermentation of TVSB.

Supplementary Materials: Supplementary materials are available online. Figures S1-S4.

Author Contributions: M.-K.K. and H.-S.C. designed overall experiments. Preparation of plant materials and fermentation work were performed by D.-W.K., M.-J.K. and D.-H.K. HPLC analysis were performed by M.-J.K. G.-Y.K. and J.-K.K. M.-J.K. and D.-H.K. performed antioxidant activity and enzyme assays. Y.-H.K. performed structural elucidation of LC-MS data. M.-K.K. and Y.-H.K. drafted the manuscript. Y.A.G. organized new supplementary data and carried out major revision of the manuscript. All authors read and approved the final manuscript.

Funding: This work was supported by 2017 Regional Food Strategy Development Project (Grant number: PJ0610240-000), Imsil-gun, Jeonbuk, Republic of Korea.

Acknowledgments: The authors would like to thank Center for University-Wide Research Facilities, Chonbuk National University, for providing help with LC-MS analysis.

Conflicts of Interest: The authors declare no conflict of interest. 


\section{References}

1. Wiart, C. A note on Toxicodendron vernicifluum (Stokes) F.A. Barkley. Food Chem. Toxicol. 2014, 64, 410. [CrossRef] [PubMed]

2. Zhao, M.; Liu, C.; Zheng, G.; Wei, S.; Hua, Z. Comparative studies of bark structure, lacquer yield and urushiol content of cultivated Toxicodendron vernicifluum varieties. N. Z. J. Bot. 2013, 51, 13-21. [CrossRef]

3. Kim, J.H.; Shin, Y.C.; Ko, S.G. Integrating traditional medicine into modern inflammatory diseases care: Multitargeting by Rhus verniciflua Stokes. Mediat. Inflamm. 2014. [CrossRef] [PubMed]

4. Choi, W.C.; Jung, H.S.; Kim, K.S.; Lee, S.K.; Yoon, S.W.; Park, J.H.; Kim, S.H.; Cheon, S.H.; Eo, W.K.; Lee, S.H. Rhus verniciflua Stokes against advanced cancer: A perspective from the Korean integrative cancer center. J. Biomed. Biotechnol. 2012. [CrossRef]

5. Liu, C.S.; Nam, T.G.; Han, M.W.; Ahn, S.M.; Choi, H.S.; Kim, T.Y.; Chun, O.K.; Koo, I.K.; Kim, D.O. Protective effect of detoxified Rhus verniciflua Stokes on human keratinocytes and dermal fibroblasts against oxidative stress and identification of the bioactive phenolics. Biosci. Biotechnol. Biochem. 2013, 77, 1682-1688. [CrossRef]

6. Lim, K.T.; Hu, C.; Kitts, D.D. Antioxidant activity of a Rhus verniciflua Stokes ethanol extract. Food Chem. Toxicol. 2001, 39, 229-237. [CrossRef]

7. Kim, M.O.; Yang, J.F.; Kwon, Y.S.; Kim, M.J. Antioxidant and anticancer effects of fermented Rhus verniciflua stem bark extracts in HCT-116 cells. ScienceAsia 2015, 41, 322-328. [CrossRef]

8. Jeon, W.K.; Lee, J.H.; Kim, H.K.; Lee, A.Y.; Lee, S.O.; Kim, Y.S.; Ryu, S.Y.; Kim, S.Y.; Lee, Y.J.; Ko, B.S. Anti-platelet effects of bioactive compounds isolated from the bark of Rhus verniciflua Stokes. J. Ethnopharmacol. 2006, 106, 62-69. [CrossRef]

9. Lee, J.H.; Kim, M.; Chang, K.H.; Hong, C.Y.; Na, C.S.; Dong, M.S.; Lee, D.; Lee, M.Y. Antiplatelet effects of Rhus verniciflua stokes heartwood and its active constituents-fisetin, butein, and sulfuretin-in rats. J. Med. Food. 2015, 18, 21-30.

10. Lee, E.J.; Lee, G.H.; Sohn, S.H.; Bae, H.S. Extract of Rhus verniciflua Stokes enhances Th1 response and NK cell activity. Mol. Cell. Toxicol. 2016, 12, 399-407. [CrossRef]

11. Byun, J.S.; Han, Y.H.; Hong, S.J.; Hwang, S.M.; Kwon, Y.S.; Lee, H.J.; Kim, S.S.; Kim, M.J.; Chun, W.J. Bark constituents from mushroom-detoxified Rhus verniciflua suppress kainic acid-induced neuronal cell death in mouse hippocampus. Korean J. Physiol. Pharmacol. 2010, 14, 279-283. [CrossRef]

12. Cho, N.K.; Choi, J.H.; Yang, H.J.; Jeong, E.J.; Lee, K.Y.; Kim, Y.C.; Sung, S.H. Neuroprotective and anti-inflammatory effects of flavonoids isolated from Rhus verniciflua in neuronal HT22 and microglial BV2 cell lines. Food Chem. Toxicol. 2012, 50, 1940-1945. [CrossRef]

13. Kim, K.H.; Moon, E.J.; Choi, S.U.; Pang, C.H.; Kim, S.Y.; Lee, K.R. Identification of cytotoxic and anti-inflammatory constituents from the bark of Toxicodendron vernicifluum (Stokes) F. A. Barkley. J. Ethnopharmacol. 2015, 162, 231-237. [CrossRef]

14. Lee, J.C.; Lee, K.Y.; Kim, J.; Na, C.S.; Jung, N.C.; Chung, G.H.; Jang, Y.S. Extract from Rhus verniciflua Stokes is capable of inhibiting the growth of human lymphoma cells. Food Chem. Toxicol. 2004, 42, 1383-1388. [CrossRef]

15. Lee, S.H.; Choi, W.C.; Yoon, S.W. Impact of standardized Rhus verniciflua Stokes extract as complementary therapy on metastatic colorectal cancer: A Korean single-center experience. Integr. Cancer Ther. 2009, 8, 148-152. [CrossRef]

16. Rayne, S.; Mazza, G. Biological activities of extracts from Sumac (Rhus spp.): A review. Plant Foods Hum. Nutr. 2007, 62, 165-175. [CrossRef]

17. Gross, M.; Baer, H.; Fales, H.M. Urushiols of poisonous Anacardiaceae. Phytochem. 1975, 14, $2263-2266$. [CrossRef]

18. Ma, X.M.; Lu, R.; Miyakoshi, T. Recent advances in research on lacquer allergy. Allergol. Int. 2012, 61, 45-50. [CrossRef]

19. Choi, H.S.; Kim, M.K.; Park, H.S.; Yun, S.E.; Mun, S.P.; Kim, J.S.; Sapkota, K.; Kim, S.; Kim, T.Y.; Kim, S.J. Biological detoxification of lacquer tree (Rhus verniciflua Stokes) stem bark by mushroom species. Food Sci. Biotechnol. 2007, 16, 935-942.

20. Cheong, S.H.; Choi, Y.W.; Min, B.S.; Choi, H.Y. Polymerized urushiol of the commercially available Rhus product in Korea. Ann. Dermatol. 2010, 22, 16-20. [CrossRef] 
21. Sapkota, K.; Kim, S.; Kim, M.K.; Kim, S.J. A detoxified extract of Rhus verniciflua Stokes upregulated the expression of BDNF and GDNF in the rat brain and the human dopaminergic cell line SH-SY5Y. Biosci. Biotechnol. Biochem. 2010, 74, 1997-2004. [CrossRef]

22. Shin, S.H.; Koo, K.H.; Bae, J.S.; Cha, S.B.; Kang, I.S.; Kang, M.S.; Kim, H.S.; Heo, H.S.; Park, M.S.; Gil, G.H.; et al. Single and 90-day repeated oral dose toxicity studies of fermented Rhus verniciflua stem bark extract in Sprague-Dawley rats. Food Chem. Toxicol. 2013, 55, 617-626. [CrossRef]

23. Djakpo, O.; Yao, W. Rhus chinensis and Galla chinensis-Folklore to modern evidence: Review. Phytother. Res. 2010, 24, 1739-1747. [CrossRef]

24. Jin, M.J.; Kim, I.S.; Park, J.S.; Dong, M.S.; Na, C.S.; Yoo, H.H. Pharmacokinetic profile of eight phenolic compounds and their conjugated metabolites after oral administration of Rhus verniciflua extracts in rats. J. Agric. Food Chem. 2015, 63, 5410-5416. [CrossRef]

25. Jang, J.Y.; Shin, H.; Lim, J.W.; Ahn, J.H.; Jo, Y.H.; Lee, K.Y.; Hwang, B.Y.; Jung, S.J.; Kang, S.Y.; Lee, M.K. Comparison of antibacterial activity and phenolic constituents of bark, lignum, leaves and fruit of Rhus verniciflua. PLoS ONE 2018, 13, e0200257.

26. Rivera-Hoyos, C.M.; Morales-Álvarez, E.D.; Poutou-Piñales, R.A.; Pedroza-Rodríguez, A.M.; Rodríguez-Vázquez, R.; Delgado-Boada, J.M. Fungal laccases. Fungal Biol. Rev. 2013, 7, 67-82. [CrossRef]

27. Minussi, R.C.; Pastore, G.A.; Durán, N. Potential applications of laccase in the food industry. Trends Food Sci. Technol. 2002, 13, 205-216. [CrossRef]

28. Ghidouche, S.; Es-Safi, N.E.; Ducrot, P.H. Trtametes versicolor laccase mediated oxidation of flavonoids. Influence of the hydroxylation pattern of ring B of flavonols. Amer. J. Food Technol. 2007, 2, 630-640.

29. Kumanotani, J. Enzyme catalyzed durable and authentic oriental lacquer: A natural microgel-printable coating by polysaccharide-glycoprotein-phenolic lipid complexes. Prog. Org. Coat. 1998, 34, 135-146. [CrossRef]

30. Lu, R.; Miyakoshi, T. Studies on acetone powder and purified Rhus laccase immobilized on zirconium chloride for oxidation of phenols. Enzyme Res. 2012, 2012, 375309. [CrossRef]

31. Motoda, S. Purification and characterization of polyphenol oxidase from Trametes sp. MS39401. J. Biosci. Bioeng. 1999, 87, 137-143. [CrossRef]

32. Burke, R.M.; Cairney, J.W.G. Laccases and other polyphenol oxidases in ecto- and ericoid mycorrhizal fungi. Mycorrhiza 2002, 12, 105-116. [CrossRef]

33. Martínková, L.; Kotik, M.; Marková, E.; Homolka, L. Biodegradation of phenolic compounds by Basidiomycota and its phenol oxidases: A review. Chemosphere 2016, 149, 373-382. [CrossRef]

34. Kubo, I.; Nihei, K.I.; Shimizu, K. Oxidation products of quercetin catalyzed by mushroom tyrosinase. Bioorg. Med. Chem. 2004, 12, 5343-5347. [CrossRef]

35. Barry, K.M.; Davies, N.W.; Mohammed, C.L. Identification of hydrolysable tannins in the reaction zone of Eucalyptus nitens wood by high performance liquid chromatography-electrospray ionisation mass spectrometry. Phytochem. Anal. 2001, 12, 120-127. [CrossRef]

36. Gómez-Caravaca, A.M.; López-Cobo, A.; Verardo, V.; Segura-Carretero, A.; Fernádez-Gutíerrez, A. HPLC-DAD-q-TOF-MS as a powerful platform for the determination of phenolic and other polar compounds in the edible part of mango and its by-products (peel, seed, and seed husk). Electrophoresis 2016, 37, 1072-1084. [CrossRef]

37. Abu-Reidah, I.M.; Ali-Shtayeh, M.S.; Jamous, R.M.; Román, D.A.; Segura-Carretero, A. HPLC-DAD-ESI-MS/MS screening of bioactive components from Rhus coriaria L. (Sumac) fruits. Food Chem. 2015, 166, 179-191. [CrossRef]

38. Gordon, A.; Jungfer, E.; da Silva, B.A.; Maia, J.G.S.; Marx, F. Phenolic constituents and antioxidant capacity of four underutilized fruits from the Amazon region. J. Agric. Food Chem. 2011, 59, 7688-7699. [CrossRef]

39. Abdel-Nabey, M.A.; Sherief, A.A.; El-Tanash, A.B. Tannin biodegradation and some factors affecting tannase production by two Aspergillus sp. Biotechnol. 2011, 10, 149-158. [CrossRef]

40. Sugimoto, K.; Nakagawa, K.; Hayashi, S.; Amakura, Y.; Yoshimura, M.; Yoshida, T.; Yamaji, R.; Nakano, Y.; Inui, H. Hydrolysable tannins as antioxidants in the leaf extract of Eucalyptus globulus possessing tyrosinase and hyaluronidase inhibitory activities. Food Sci. Technol. Res. 2009, 15, 331-336. [CrossRef]

41. Yao, J.; Guo, G.S.; Ren, G.H.; Liu, Y.H. Production, characterization and applications of tannase. J. Mol. Catal. B: Enzym. 2014, 101, 137-147. [CrossRef] 
42. Govindarajan, R.K.; Revathi, S.; Rameshkumar, N.; Krishnan, M.; Kayalvizhi, N. Microbial tannase: Current perspectives and biotechnological advances. Biocatal. Agric. Biotechnol. 2016, 6, 168-175. [CrossRef]

43. Xiao, Y.; Xing, G.; Rui, X.; Li, W.; Chen, X.; Jiang, M.; Dong, M. Enhancement of the antioxidant capacity of chickpeas by solid state fermentation with Cordyceps militaris SN-18. J. Funct. Foods 2014, 10, 210-222. [CrossRef]

44. Gorinstein, S.; Haruenkit, R.; Poovarodom, S.; Vearasilp, S.; Ruamsuke, P.; Namiesnik, J.; Leontowicz, M.; Leontowicz, H.; Suhaj, M.; ShengSome, G.P. Analytical assays for the determination of bioactivity of exotic fruits. Phytochem. Anal. 2010, 355-362. [CrossRef]

45. Pellegrini, N.; Serafini, M.; Colombi, B.; Del Rio, D.; Salvatore, S.; Bianchi, M.; Brighenti, F. Total antioxidant capacity of plant foods, beverages and oils consumed in Italy assessed by three different in vitro assays. J. Nutr. 2003, 2812-2819. [CrossRef]

46. Shama, P.; Singh, R.P. Evaluation of antioxidant activity in foods with special reference to TEAC method. Am. J. Food Technol. 2013, 8, 83-101.

47. Kurisawa, M.; Chung, J.E.; Uyama, H.; Kobayashi, S.; Uyama, H.; Kobayashi, S. Enzymatic synthesis and antioxidant properties of poly(rutin). Biomacromolecules 2003, 4, 1394-1399. [CrossRef]

48. Riebel, M.; Sabel, A.; Claus, H.; Fronk, P.; Xia, N.; Li, H.; König, H.; Decker, H. Influence of laccase and tyrosinase on the antioxidant capacity of selected phenolic compounds on human cell lines. Molecules 2015, 20, 17194-17207. [CrossRef]

49. Sánchez-Mundo, M.L.; Escobedo-Crisantes, V.M.; Mendoza-Arvizu, S.; Jaramillo-Flores, M.E. Polymerization of phenolic compounds by polyphenol oxidase from bell pepper with increase in their antioxidant capacity. CYTA J. Food 2016, 14, 594-603.

50. Chandra, S.; Khan, S.; Avula, B.; Lata, H.; Yang, M.H.; ElSohly, M.A.; Khan, I.A. Assessment of total phenolic and flavonoid content, antioxidant properties, and yield of aeroponically and conventionally grown leafy vegetables and fruit crops: A comparative study. Evid. Based Complement. Alternat. Med. 2014. [CrossRef]

51. Zhishen, J.; Mengcheng, T.; Jianming, W. The determination of flavonoid contents in mulberry and their scavenging effects on superoxide radicals. Food Chem. 1999, 64, 555-559. [CrossRef]

52. Chen, Y.; Hagerman, A.E. Characterization of soluble non-covalent complexes between bovine serum albumin and $\beta-1,2,3,4,6-$ penta-O-galloyl-D-glucopyranose by MALDI-TOF MS. J. Agric. Food Chem. 2004, 52, 4008-4011. [CrossRef]

53. Mondal, K.C.; Banerjee, D.; Jana, M.; Pati, B.R. Colorimetric assay method for determination of the tannase activity. Anal. Biochem. 2001, 295, 168-171. [CrossRef]

54. Thaipong, K.; Boonprakob, U.; Crosb, K.; Cisneros-Zevallos, L.; Byrne, D.H. Comparison of ABTS, DPPH, FRAP, and ORAC assays for estimating antioxidant activity from guava fruit extracts. J. Food Composit. Anal 2006, 19, 669-675. [CrossRef]

55. Benzie, I.F.F.; Strain, J.J. The ferric reducing ability of plasma (FRAP) as a measure of "antioxidant power": The FRAP assay. Anal. Biochem. 1996, 239, 70-76. [CrossRef]

Sample Availability: Samples are available from the authors.

(C) 2019 by the authors. Licensee MDPI, Basel, Switzerland. This article is an open access article distributed under the terms and conditions of the Creative Commons Attribution (CC BY) license (http:/ / creativecommons.org/licenses/by/4.0/). 